\title{
An Exploratory Study on the Effect of an Approach-Avoidance Coping Program on Perceived Stress and Physical Energy among Police Officers
}

\author{
Mark H. Anshel ${ }^{1 *}$, Thomas M. Brinthaupt ${ }^{2}$ \\ ${ }^{1}$ Department of Health and Human Performance, Middle Tennessee State University, Murfreesboro, USA \\ ${ }^{2}$ Department of Psychology, Middle Tennessee State University, Murfreesboro, USA \\ Email: ${ }^{*}$ Mark.Anshel@mtsu.edu
}

Received 14 February 2014; revised 15 March 2014; accepted 12 April 2014

Copyright (C) 2014 by authors and Scientific Research Publishing Inc.

This work is licensed under the Creative Commons Attribution International License (CC BY).

http://creativecommons.org/licenses/by/4.0/

(c) (i) Open Access

\section{Abstract}

The purpose of this exploratory study was to examine the effects of an approach-avoidance coping skills program on changes in perceived stress and physical energy among police officers. Participants included 11 police officers in a medium-sized US city who volunteered to engage in a coping skills program due to experiencing excessive job-related stress. The officers completed an initial 2-hour seminar on approach-avoidance coping skills and met privately with a stress management coach. Analyses indicated reduced use of approach coping strategies that approached significance. Participants reported significantly higher levels of physical energy at posttest compared to pretest. Higher levels of physical energy were also associated with greater use of avoidance coping at posttest. Personal narratives by selected officers indicated a particularly stressful work environment, and that the officers adopted many of the approach and avoidance coping skills in reducing job-related stressors. The results suggest that the approach-avoidance coping framework may be an effective means for managing acute police stress.

\section{Keywords}

Law Enforcement, Police Stress, Approach-Avoidance Coping

\section{Introduction}

Stress in law enforcement is ubiquitous. Hart, Wearing, and Headey (1995) found that "police organizations are the main source of psychological distress among police officers” (p. 150). The inability to cope with police

${ }^{*}$ Corresponding author.

How to cite this paper: Anshel, M. H., \& Brinthaupt, T. M. (2014). An Exploratory Study on the Effect of an ApproachAvoidance Coping Program on Perceived Stress and Physical Energy among Police Officers. Psychology, 5, 676-687. 
stress results in reduced passion for the job, sleep deprivation, increased chronic stress, burnout, and quitting the force (Slate, Johnson, \& Colbert, 2007). Examples of common sources of police stress include lack of supervisory support, poor communication with work colleagues, sexual harassment (primarily reported by female officers), exposure to violent or aggressive actions by others, responding to an emergency, and dealing with the court system (Aumiller et al., 2007). Verbal abuse coming from colleagues, supervisors, and the public is particularly noxious to the officers' mental well-being (Behr, 2000; Kirkmeyer, 1988; Shepherd \& Hodgkinson, 1990). Unhealthy habits, such as a sedentary lifestyle and poor nutrition, exacerbate the effects of stress, resulting in weight gain and obesity (Wyllie, 2011). Studies on the effects of interventions to change these unhealthy habits and improve coping skills of officers have been relatively rare. In this study, we examine whether perceived police stress can be reduced through the use of effective coping strategies.

Coping is typically defined as the ability to manage stressful feelings and to deal with the unpleasant events from which those feelings originate. Coping strategies reflect a person's use of specific and planned techniques, expressed in either cognitive or behavioral form (Anshel, Kang, \& Miesner, 2010). These techniques can build personal resources, such as confidence, hardiness, and self-control, or manipulate environmental demands that reduce stressful feelings, such as social support or the removal of external threatening events or stimuli (Krohne, 1993).

Although coping frameworks abound, one framework that has been applied effectively with respect to performance psychology is approach and avoidance (Anshel et al., 2010; Krohne, 1993). Use of approach coping strategies focuses on the person's thoughts or behaviors following stressful appraisals of an event for the purpose of reducing or managing the stressful event (Anshel, 2000). Krohne (1993) refers to approach coping, what he calls vigilance, "as those strategies which are characterized by intensified intake and processing of threatening information” (p. 21). Examples of approach coping include seeking information, obtaining knowledge, verbal confrontation, planning a strategy, monitoring actions, venting emotions, and visualization. For Anshel (2000), an approach coping strategy in law enforcement reflects the person's conscious attempt to confront the threat, either directly (e.g., physical actions that help resolve the situation) or indirectly (e.g., thoughts of confrontation or planning direct action).

Avoidance coping, on the other hand, reflects a person's decision to remove oneself from a perceived threat. This might be accomplished through filtering out or ignoring information (i.e., discounting or reducing the importance of the stressor) or psychologically distancing oneself from the stressor by objectively identifying and understanding the source of stress (Anshel, 2001; Krohne, 1993; Roth \& Cohen, 1986). Perhaps not surprisingly, approach coping is used more often than avoidance coping in law enforcement (Anshel, 2011).

Researchers and practitioners agree that the main objective of coping is to use approach and avoidance strategies selectively based on various situational characteristics, and, to an extent, in response to the individual's approach or avoidance coping style. Approach and avoidance coping styles are dispositional and reflect the individual's preference to use certain types (categories) of coping strategies. Coping effectiveness is an important outcome of selecting and properly using both types of coping depending on personal and situational characteristics.

While the coping process is intended to improve the prevention and management of stress, it may not be assumed that the use of coping strategies is necessarily effective. The use of effective, or adaptive, coping strategies should resolve the stressful issue in a safe and legal manner without creating additional stress or negative emotion. Elevation of positive affect is also highly desirable. The primary focus on effective coping is to help the police officer better manage stress, thereby reducing its unpleasant effects on job performance and mental, emotional, and physical well-being.

Ineffective, or maladaptive, coping responses may exacerbate the effects of stress on a person's emotions, thoughts, and behaviors. Maladaptive coping consists of strategies that may contribute to the person's stress intensity, lead to undesirable emotions and poorer performance outcomes, and, perhaps, result in reduced job satisfaction and general physical and mental well-being (Zeidner \& Saklofske, 1996). Examples of ineffective coping strategies that have implications for law enforcement include the excessive use of alcohol, tobacco use, acute explosive anger, ingestion of hallucinogenic (mind-altering) drugs, chronic negative self-talk, impatience, premature or unnecessary anger and hostility toward others (i.e., short fuse), unneeded verbal or physical confrontation, and fighting.

There is ample evidence that coping with stress in law enforcement is often maladaptive (Anshel, 2000; Anshel, Robertson, \& Caputi, 1997; Hart et al., 1995). The results of poor coping in law enforcement include rela- 
tively high rates of divorce, thoughts of or actual suicide, negative mood, chronic anxiety, depression, ineffective communication with others, and poor performance (Rybicki \& Nutter, 2002). Thus, it is apparent that detecting and attempting to change poor coping skills is especially important among police personnel.

There is a paucity of research examining the effectiveness of coping interventions on perceived stress among police officers. The close working stations and ongoing interactions among police officers, especially when dealing with the public during an 8-hour shift, create an array of continuous sources of stress. The responsibilities of police officers on duty and the need for remaining vigilant during a typical 8-hour shift virtually mandate approach coping (Anshel, 2000). Responding to emergencies, for instance, should allocate attentional focusing to the task at hand with as few distractions as possible. This is especially true if an event or experience that the officer perceives as stressful (e.g., disparaging remarks or gestures from others) is unrelated to resolving the situation. There are times, however, when avoidance coping is not only more effective, but even potentially life-saving. An example would be when an officer is exposed to unpleasant stimuli (e.g., a negative non-verbal cue; use of profanity) but does not know its source, particularly in a high-crime location. If the officer (or anyone else) is not in harm's way and there is no apparent dangerous situation that requires monitoring by law enforcement, it may be best to ignore the transgression and move on (Anshel, 2000, 2011).

As noted earlier, police work is inherently and continuously stressful during the officers' 8-hour shift (Hassell \& Brandl, 2009). Consequently, negative emotions and feelings are not uncommon. Colleagues, emergency dispatchers, and administrators in law enforcement continuously judge work performance. While periods for rest and recovery are scheduled, the police officer remains on duty and may be called at any time to respond to an emergency, reducing or eliminating rest periods. One objective of the intervention in the current study was to assist officers in identifying the criteria for using approach and avoidance coping skills, resulting in greater coping effectiveness.

The demands of police work require effective coping skills, particularly in situations in which the officer has little control. Examples of these situations include absent co-workers on the officer's shift, receiving insults and hostile action from others, exposure to threats of violence and suicide, and actual suicide and other forms of violent behavior, all of which are coupled with a relatively low salary. In this context, effective coping skills are needed to maintain job satisfaction, good health, and effective performance. As Jenkins (1997) confirms, police officers have "a strong commitment to help others, a tolerance for time pressures and unpredictable demands, and proficiency at demanding tasks under pressure” (p. 202). There is a clear need to examine the effects of interventions that improve coping skills and enhance the energy and physical and emotional well-being of police officers.

Thus, the purposes of this exploratory study were: 1 ) to determine the effectiveness of a coping skills program on reducing perceived stress and increasing perceived energy among male and female police officers, and 2) to employ a narrative inquiry research technique to obtain insights of selected officers about their work conditions and demands that might suggest the need for certain types of coping strategies, using the approach-avoidance framework. It was hypothesized that, after the coping skills intervention, officers would use less approach and more avoidance coping and report significantly reduced perceived stress and increased perceived physical energy.

\section{Method}

\subsection{Participants}

A total of 11 full-time police officers ( 7 men, 4 women) volunteered to participate in the study. Participants were recruited from the local municipal police department of a medium-sized $(110,000+)$ city in the southeastern US. The officers were experiencing excessive job-related stress and were responding to a coping skills program offered as part of a joint grant by their police department and a local university. The officers ranged in age from 26 to 57 yrs $(M=37.82, S D=9.96)$. Seven of the 11 officers $(64 \%)$ were married. The participants served in law enforcement for an average of 9.5 years $(S D=2.77)$. Participation in the study could not be mandatory because the study followed guidelines from the university's Institutional Review Board and the city employing these police officers. There were no financial incentives for participation in the study.

\subsection{Measures}

Participants completed three questionnaires immediately prior to (pretest) and immediately after the intervention 
(post-test).

Perceived Stress Scale (PSS). Participants first completed the 10-item PSS (Cohen \& Williamson, 1988). The PSS is a frequently used and well-validated general measure of perceptions of life stress during the past month. Using a 5-point scale $(0=$ never, 4 = very often $)$, respondents rate the frequency over the past month of a variety of feelings (e.g., "been angered because of things that were outside of your control") and experiences (e.g., "felt confident about your ability to handle your personal problems"). Possible scores ranged from 0 to 40 , with higher scores denoting greater perceived stress. With the present sample, coefficient alpha reliability for the PSS was acceptable at both pretest $(r=.71)$ and posttest $(r=.79)$.

Perceived Physical Energy (PPE). The PPE consisted of a 10-item measure of respondents' current levels of physical energy. Sample items were "I feel high physical energy at work," "I consider myself physically fit," and "I wake up feeling rested." Respondents rated each item using a 5-point scale ( $0=$ strongly disagree, $4=$ strongly agree). Total scores could range from 0 to 40. Higher scores indicated higher levels of perceived physical energy. Coefficient alpha reliabilities for this measure were acceptable at both pretest $(r=.81)$ and posttest ( $r=$.89). Anshel, Umscheid, and Brinthaupt (2013) reported similarly high alpha coefficients for this measure in their study of emergency dispatchers.

Coping Style for Acute Stress (CSAS). The CSAS consisted of the officers' rating of how they typically deal with acute, highly stressful work-related events. It has been validated in a previous law enforcement study (Anshel et al., 2013). First, the officers thought of a highly stressful job-related event that they experienced in recent weeks or months. Then, they assessed how they dealt with, responded to, or coped with that event. Keeping the event in mind, respondents rated 24 adaptive and maladaptive items, using a 5-point scale $(0=$ not at all like me, 4 = always like me).

The measure included 13 items reflecting an approach coping style (e.g., "I confronted the problem," "I discussed the problem with another person”) and 11 items reflecting an avoidance coping style (e.g., "I did something else to get my mind off the situation," "I did not take the person/situation seriously"). Obtaining acceptable alpha coefficients required eliminating several approach and avoidance items. Thus, the final measures consisted of eight approach items and seven avoidance items. Scores were calculated for approach and avoidance coping by summing the relevant items for each subscale. Higher scores indicated greater use of that coping style. Coefficient alpha reliabilities for both subscales were acceptable at the pretest (approach: $r=.72$, avoidance: $r=.73$ ) and at the posttest (approach: $r=.64$, avoidance: $r=.76$ ).

\subsection{Procedures and Intervention}

Participants experienced a two-hour seminar presented in PowerPoint format that included educational materials on the proper use of approach and avoidance coping skills carried out in cognitive and behavioral form in response to typical sources of stress in law enforcement. The stressors were specific to various aspects of the officer's job, particularly unique for a given shift (e.g., overnight versus daytime).

Individualized coping skills sessions were conducted during the 10 -week intervention period and consisted of at least two 1-hour individual consulting sessions with the program's stress management coach using the approach-avoidance coping framework. The coach was not a licensed psychologist, and, therefore, restricted this consultation comments to coping skills, and did not address issues related to mental health or psychotherapy. Officers were informed they could speak with their stress management coach on a stress-related matter at any time during the study. They shared their job-related sources of acute and chronic stress. The coach would then suggest ways to cope effectively with the stressor using the approach-avoidance framework. Table 1 lists a "menu" of coping strategies that officers were taught in the program. These included approach and avoidance dimensions, and cognitive and behavior sub-dimensions in response to acute stress.

As indicated earlier, the preferred use of coping strategies in response to various types of stressors reflected the approach-avoidance coping framework. Approach coping usually consists of any thought, emotion, or action that is oriented toward the threat, such as monitoring or confronting the source of stress for the purpose of reducing stress intensity and/or improving job performance (Anshel, 2000). Examples of approach coping include seeking information, gaining knowledge, confrontation (arguing), planning, monitoring, or venting. Approach coping can be effective (adaptive), such as when seeking information, or ineffective (maladaptive), such as when using anger, fighting, or illegal behavior. 
Table 1. Selected coping strategies for police officers using approach and avoidance dimensions, and cognitive and behavior sub-dimensions in response to acute stress.

Approach-Behavior Coping

Confronting, threatening, arguing, information-seeking, social support, explaining, friendly non-verbal/verbal affirmation, verbal acknowledgment, discussing, catastrophizing, speaking to a mentor or supervisor, receiving counseling, soliciting opinions from others.

Avoidance-Behavior Coping

Walking away, social engineering (avoiding a certain location), exercise, reading, watching television, listening to music, attending church, ingesting an alcoholic beverage, recreational ctivity, engaging in sexual behavior, playing or watching sports, reading, target shooting.

\section{Approach-Cognitive Coping}

Covert rehearsal, planning, analyzing, self-talk reanalyzing, justifying, psyching-up, prayer (if related to coping with the stress), self-statements, logic/reason.

Avoidance-Cognitive Coping

Discounting, psychological distancing, labeling, empathy, thought-stopping, ignoring, self-talk, mental imagery, progressive relaxation, focusing on the next a task, prayer (if focusing on the Lord and not on the stressor).

\section{Examples of Ineffective/Maladaptive Approach and Avoidance Coping}

Excessive alcohol, smoking, mind-altering drugs, emotional eating, prolonged anger and hostility, car speeding, thoughts of selfdestructive actions, negative self-talk, rumination (repeating self-blame), resignation (helplessness/hopelessness), exhibit bad mood toward others, excessive exercise.

Avoidance coping, on the other hand, is used under conditions of low self-control over the stressful event, among other criteria (Krohne, 1993). For example, if officers experienced an unpleasant interaction with another officer or staff member, they were advised to apply avoidance coping strategies of discounting (e.g., "The dispatcher's tone of voice is not important") or psychological distancing (e.g., "Dispatcher work is a tough and stressful job so I'll not criticize the dispatcher" or "I do not like how my shift colleague keeps complaining but I will be a good listener and be supportive"). Labeling could be used with a member of the public (e.g., "The person who just insulted me is not normal, so ignore him"). Group discussions with the study participants strongly suggested that most members of law enforcement, including officers, detectives, emergency dispatchers, and administrators tend to use approach, not avoidance, coping strategies. This is likely due to their need to remain vigilant and in control of most situations (Bramson, 1981). Table 1 categorizes the coping skills as approach-cognitive, approach-behavior, avoidance-cognitive, and avoidance-behavior that were reviewed in the seminar and used later in the individualized officer consultations.

\subsection{Officer Narratives}

Intervention studies with small sample sizes often require additional information that deepens the understanding of the factors, conditions, and issues explaining the results and the intervention's effectiveness. The research procedure that addresses one's experiences, thoughts, and emotions is called narrative inquiry (NI; Clandinin \& Connelly, 2000). In the current study, disclosing personal stories provided insights into selected officer thoughts and behavioral patterns that helped explain their needs, habits, professional and personal goals, and both healthy and unhealthy behavior patterns. NI consisted of the officers providing information about their experiences and personal feelings related to their job while participating in the study. These insights are intended to explain and enhance the effects of the intervention.

Following the initial coping skills seminar, the stress management coach met privately with each of the 11 officers for two 1-hour sessions to discuss their most intense professional sources of acute (or chronic) stress, and ways in which to cope more effectively using the approach-avoidance framework. It was important to personalize the coping program so that officers received an intervention that was as compatible as possible with their needs. The narratives also provided important information to the stress management coach about areas that needed immediate attention. Examples of these areas included: 1) determining which sources of stress were changeable and under the officer's control, 2) identifying the best coping strategies in responses to these stressors, 3) deciding on the sources of stressful conditions that were less possible to change, such as a supervisor's actions, the actions or judgments of the court, or inappropriate communication from others, and 4) establishing how to apply the coping strategies that would be optimally effective for these non-controllable sources of stress. It was understood that all information obtained in the narrative was strictly confidential and not available to other personnel in the department. 


\section{Results}

\subsection{Coping Styles, Perceived Stress, and Perceived Physical Energy}

In order to test the main hypotheses of this study, we conducted paired-samples t-tests comparing pre- and post-intervention measures. Participants showed a tendency to report fewer approach coping strategies from pre$(M=27.91, S D=5.34)$ to post-intervention $(M=24.00, S D=6.69)$, approaching but not quite reaching statistical significance using an alpha of $p<.05, t(10)=2.05, p=.07$. Analysis of avoidance coping strategy scores showed no change from pre- to post-intervention $(p=.91)$.

The data indicated that perceived stress scores decreased from pretest $(M=13.27, S D=4.20)$ to posttest $(M=$ $10.55, S D=4.52)$. However, this reduction in PSS scores did not reach statistical significance, $t(10)=1.72, p$ $=.12$.

Analysis of the perceived physical energy measure revealed a significant pretest/posttest effect, with posttest scores $(M=26.36, S D=8.03)$ higher than pretest scores $(M=17.09, S D=7.37), t(10)=3.22, p=.009$.

Finally, we examined the Pearson correlations among the major measures at pretest and posttest for all participants. This analysis indicated that pretest perceived physical energy was significantly and negatively related to the use of pretest avoidance coping strategies, $r(9)=-.60, p=.05$. This relationship, however, was reversed at posttest, $r(9)=.60, p=.05$. That is, more physical energy accompanied greater use of avoidance coping after the coping skills intervention. In addition, posttest perceived physical energy was significantly and negatively correlated with perceived stress, $r(9)=-.61, p=.05$. No other relationships reached statistical significance.

\subsection{Police Officer Narratives}

As indicated earlier, a stress management coach met with the officers individually to discuss their sources of stress and possible coping strategies to attenuate those stressors. Following are the narratives from three of the officers in this study and the coach's reactions using the approach-avoidance (cognitive-behavior) coping conceptual framework. The primary goal in the individual interventions was to assist officers in the proper selection and application of each category of coping, if possible, compatible with the officer's coping style.

The individual meetings between police officers and their stress management coach lasted from 30 to 60 minutes (mean time $=47.5 \mathrm{~min}$.). Meeting locations varied, including a room in the police department or a public café, as determined by the officer's preference. The meetings consisted of the following protocol: a) officers disclosed one or two areas of professional practice that were sources of intense stress, either chronic (e.g., relationship with a supervisor or colleague; feeling fatigued from high job demands and excessive hours) or acute (e.g., properly dealing with comments from others, reacting to a person's display of disrespect); b) the officers would then disclose how they typically handled the stressful situation and whether or not their reaction was effective; and finally, c) the coach and officers examined alternative coping strategies using the approach-avoidance framework. In most instances it was apparent that officers were reacting to stress using approach coping, either in cognitive (e.g., unpleasant thoughts, intense emotions) or behavioral form (e.g., confrontation, taking out their negative feelings on a family member).

The meeting's last segment consisted of discussing and agreeing to use a particular coping strategy within the approach-avoidance framework that might be more effective in reducing the frequency and intensity of stress. Obtaining quantitative data on the individual meetings was neither desirable nor practical. Information that might identify the officer is omitted from these narratives. The officers were invited to follow up this meeting with their coach either in person, by phone, or via e-mail at any time during the 10-week intervention period. The purpose of the second meeting was to discuss if the suggested coping strategy was efficacious and/or to discuss additional areas of stress that needed attention.

The officers reported they had attempted to use new coping strategies with mixed success, but agreed that additional practice was needed to improve coping effectiveness. It was also their intention to maintain efforts to learn and effectively use these new coping strategies.

\subsection{Police Officer 1 (Female)}

"I like being a police officer but the job is more difficult when some of the other officers act very unprofessional. Some of them are simply sexist, trying to take advantage of a female officer. A few others like to tell jokes that are meant to embarrass me. And some of them just resent female officers and refuse to have a female partner. So 
I have to do my best to ignore these people because it makes no sense to complain to anyone unless I was touched inappropriately, and that has not happened. Things can turn nasty if I don't ignore most of that stuff or just laugh it off. I just want people to do their jobs. I make sure I am as good as I can be. Still, sometimes things get to me and I have to learn to ignore people who say nasty stuff to me or make very unfair complaints about how I do my job. We all know that what we do is important and that is the important thing; to remember why I'm a cop. I just cannot let a few of these guys get to me."

Coach's reaction. This officer is experienced and highly skilled, but feels she needs to gain more experience and the respect of her colleagues before she can apply for promotion. She is a bit frustrated by how female officers, but particularly she, is perceived by a few colleagues and is waiting for things to change on their own, which is not likely to happen. Her focus has to be on how to handle an unpleasant situation, particularly when she is addressed inappropriately by a few fellow officers. Her career will not be advanced and others will make her life miserable if she was to complain formally about the actions of just a few. The coping skills she was taught served to increase her sense of self-control, since she has little control over the actions of others. Three coping strategies were recommended:

Avoidance-cognitive coping. In response to being criticized or teased by others, it was important that she put this issue in perspective through the use of psychological distancing in three ways: a) Instead of focusing on her critic, her attentional focus should be on recognizing her own competence and always treating other work colleagues with respect. b) She should avoid responding in an angry or critical manner; perhaps take a deep breath and keep moving forward to the next task or, if feasible, to physically remove herself from the current environment. c) She should remember that people (in all professions) occasionally reflect their own low self-image, deep insecurities, or have a disrespectful opinion of others based on the culture in which they were raised or a bias toward certain personal characteristics of others. Her goal is to distance herself from these individuals and try not to take their comments personally.

Approach-behavior coping. This officer is going to make a special effort to be polite and professional to her critics/teasers by initiating verbal greetings during roll call or at other times, or even to seek information from these individuals if she feels they have particular expertise. The goal here is to shift attention away from personal criticism and to redirect the conversation toward professional matters, at least occasionally. This is intended to build rapport with others and focus on professional, not personal, matters. She may also offer verbal compliments when she sees her co-workers performing well to further reinforce their professional behavior. In the opposite direction, if she is genuinely insulted by these remarks she can inform the offending officer(s) — quietly and, if possible, away from others to prove her sincerity - that she will file a complaint against him if these remarks continue.

Approach-cognitive coping. The officer feels frustrated with a few members of her shift. She is going to monitor what appears to upset her (e.g., co-worker remarks, feeling disrespected, continually thinking about the disparaging remarks directed at her, and her defensive reactions to them). She can visualize situations in which these remarks are experienced, and to anticipate and covertly rehearse her professional responses to those remarks. She will be prepared to react with specific coping strategies, such as laughter (i.e., disarming her offending colleague by laughing at the remark and treating it as the person's poor attempt at humor, rather than being a victim and target of the remark).

\subsection{Police Officer 2 (Male)}

"I have two stressors in my career that come to mind, both not under my control and very frustrating, dealing with certain emergency dispatchers and coping with the court system. I found certain coping strategies in your seminar helped me handle the negative attitude of certain dispatchers-particularly two that I do not feel are properly trained and who don't seem to know what they are doing. The coping skills have not improved my job satisfaction in this area, but at least I am able to adjust to their antics. The other issue is something that almost drives me to quit this job. I work my ass off to put bad guys in jail and the judge gives him a slap on the wrist or keeps the bail very low so he can keep walking the streets. Drives me nuts.” While dealing with the court system was a common stressor among many police officers, this narrative will focus on the relationship with dispatchers.

Coach's commentary. This officer struggles with what he perceives as ineptitude by at least two dispatchers, and is often annoyed when they do not perform according to his standards and expectations. Unfortunately, the 
officer has very little control over these stress sources and must rely on avoidance coping strategies for both, so that he can maintain or improve his job satisfaction. We reviewed coping skills that centered primarily on avoidance-cognitive coping, but also applying approach-behavior with the dispatcher. It should be noted that the department does not have an effective strategy or policy for having the dispatchers and officers for each shift interact and become better acquainted. While the dispatchers for each shift are in the room during roll call (at the start of the new shift), they have been observed sitting together in the back and not interacting with the officers for that shift. Thus, the intended outcome of improving social and professional rapport between dispatchers and officers, which is needed, is usually unmet.

Approach-behavior. Instead of an angry response following a dispatcher's negative comments or the perception that she is lacking in skills (both of which reflect ineffective, or maladaptive, coping), two actions should be taken, depending on the situation: a) take a deep breath and feel in emotional control (i.e., "don't lose it”), and b) engage with the dispatcher constructively, either by seeking further information and clarification (e.g., "Sorry, please repeat; I missed your message") or by offering constructive information that will improve the dispatcher's performance (e.g., "I am not hearing the end of your sentences; you may be lifting your finger off the radio too soon"). If the suggestion is given with no negative emotion and in the spirit of working jointly to meet situational demands, the dispatcher should end the dialogue with, "I appreciate the feedback." Dispatchers and officers should act as teammates, not as opponents.

Avoidance-cognitive. Situations in which the dispatcher is not performing up to officer expectations or is acting unprofessionally require mental "dismissal" of the dispatcher's behavior and obtaining the necessary information as quickly and accurately as possible. Avoidance coping is optimally effective when there is insufficient time to address the stressor or if the situation warrants the officer's immediate attention. Another avoidance-cognitive coping strategy is "labeling." The officer can designate the dispatcher—covertly—as "ineffective" or perhaps a more harsh label ("what a loser" or "there goes Ms/Mr. Negative again"). The goal is to move quickly beyond the stressful situation and to stay focused on the task at hand or to be prepared for the next event with as little stress as possible.

\subsection{Police Officer 3 (Male)}

"I really get upset when someone on the street shows disrespect toward me when I am driving in my cruiser. Being 'flipped off' is common, especially in a 'bad' neighborhood. I do not usually ignore abusive language-spoken or unspoken. If someone disrespects me I will approach him and get into his face. I might threaten jail if I feel he is not acting irresponsibly, abusing me, or exhibit signs of drug or alcohol use. Certainly if he has broken the law — and showing abuse toward a police officer is against the law-I will consider bringing him in. So, you might say it is difficult to ignore idiots on the street, although I probably need to do a better job of picking my battles and learning when it's a good idea to ignore certain things.”

Coach's commentary. This officer has been around many years, so he is well aware of how to do his job. Nevertheless, he is struggling in his professional and personal life, and feels stressed daily. His home environment is not conducive to recovery from the "storms" of his job, making emotional recovery while away from work very difficult. There is concern about his overall mental health and the need to deal properly with his "short fuse." The following coping strategies seem appropriate, in addition to marital counseling.

Avoidance-behavior. This officer needs to begin an exercise program or some other form of enjoyable physical activity, and generate other forms of recovery. Exercise and other forms of recovery direct the person's attentional focus onto the activity and not on the causes and sources of chronic stress. Other recovery strategies might include taking time to be with one or more friends, walking through the mall (whether or not shopping is an option), hiking outdoors, watching a film or television, and even driving out of town to take a brief trip. Recovery strategies must have at least three characteristics: they are enjoyable, increase energy, and distract the person from "regular" job-related tasks.

Approach-behavior. This officer is struggling with his marriage and may anticipate a divorce. Thus, he needs to confront this stressful part of his life by applying approach-behavior coping in three ways: 1) approaching his wife to seek information about how she views their marital future, 2) marital counseling if they both feel the marriage can be saved, but if a divorce is pending, 3) legal assistance to ensure that divorce conditions are handled properly and meet the family's financial and legal needs. In terms of dealing with an unpleasant person, approach-behavior coping is usually counterproductive; it is not in the officer's best interest to confront some- 
one in the street if they are not breaking the law and they may have a weapon. If the person is making an impolite gesture, ignoring the person (avoidance-cognitive) may be a better way to cope while still doing his job. A more positive example of approach-behavior coping is to establish rapport with the offender, perhaps by starting a conversation, rather than to engage in confrontation.

Avoidance-cognitive. This form of coping is probably the most constructive for the situation described here. Avoidance-cognitive coping allows the officer to dismiss the person's actions as that of a mentally unstable or troubled person (i.e., discounting, labeling) not worthy of directing additional energy or attention unless there is clear detection of danger or law breaking. Coping with adversity includes knowing when to "shut out" unpleasant aspects of the environment in performing law enforcement duties.

\section{Discussion}

The purpose of this study was to examine the effect of a coping skills program on reducing perceived stress and improving physical energy among male and female police officers. The approach-avoidance coping framework was applied to improve the officers' coping skills and reduce their perceived stress. It was expected that, after the coping skills intervention, officers would use less approach and more avoidance coping and report significantly reduced perceived stress and increased perceived physical energy. These hypotheses were partially supported.

Of particular importance in this study - the primary conceptual framework and intervention strategy-was improving the officers' coping skills using the approach-avoidance coping framework. A primary objective was to reduce the extent to which the officers applied approach coping and to increase the frequency and effectiveness of using avoidance coping strategies. The results indicated that the participants tended to report fewer approach coping strategies from pre- to post-test, but did not change in their use of avoidance coping strategies. Whereas avoidance coping did not change from pre- to post-intervention, the nature of the officers' avoidance coping (e.g., the specific kinds of strategies they ended up using) could well have shifted from less to more adaptive. The coping skills measure used was not sensitive enough to capture this possibility. Additional research examining the quality as well as the quantity of approach and avoidance skills after participating in a coping-skills intervention is warranted.

An additional hypothesis was that program participants would experience significantly increased physical energy from pre- to post-intervention. This hypothesis was supported. In addition, physical energy was positively related to increased use of avoidance coping and decreased perceived stress at post-test.

One objective of avoidance coping is to allow the person to minimize the importance of selected stressful events, while giving optimal concentration to more important situations that warrant immediate attention, more energy, and, often in law enforcement, a physical response (Anshel et al., 1997; Roth \& Cohen, 1986). Avoidance allows the stressed individual, in this case, law enforcement, to reduce the importance of selected stressors and, instead, to focus on more meaningful, possibly life-threatening situations that require greater vigilance and concentration. Some stressors are simply less important or controllable than others, and at times, some of these “unimportant” stressors need to be ignored.

The probable cause of the increased energy was due, ostensibly, to participating in the coping skills program, although the lack of a control group prohibits drawing that conclusion. However, the focus of this program was to apply the types of coping skills, using the approach-avoidance framework, that improve coping effectiveness thereby reducing perceived stress. Additional research that includes a control group and a larger sample is necessary to provide more direct evidence of the relationship between the use of specific coping skills and perceived energy.

\section{Officer Narratives}

Narratives provided by the officers appear to lend further credence to the positive influence of an approach-avoidance coping skills program on perceived stress. It was apparent that police officers found it advantageous to discuss their job-related stress with the stress management coach. Coping is a skill that requires instruction, practice, monitoring its effectiveness, and determining whether the coping strategies are effective in preventing or reducing perceived psychosocial stress. It was also clear that the officers found it helpful to share some of their personal and professional "storms" with the stress management coach. Personal meetings provided the officer with the needed privacy and opportunity to "open up” and disclose highly confidential information. 
In turn, this further allowed the coach to target specific issues and stressors that warranted the optimal use of coping skills.

Along these lines, it was imperative that officers realized prior to and during their involvement in the program that these sessions were instructional, and not an attempt to conduct psychotherapy. If an officer expressed concern about a particular issue that warranted the skills of a mental health professional (e.g., marriage counseling, depression, or burnout), he or she was referred to a licensed psychologist. In fact, each officer expressed their preference to work on their coping skills with a stress management coach rather than a licensed psychologist due to the officers' perception that there was no concern about the officer's mental health nor a desire to seek professional counseling. The department employed two licensed psychologists if officers volunteered or were required to receive psychotherapy.

One objective of this study's intervention was to instruct the officers on learning, selecting, and properly applying approach or avoidance coping strategies following acute or chronic stress. These strategies were discussed at length in private settings with their coach. All officers indicated they had used the coping skills discussed in the individual sessions and found the approach-avoidance framework and the coping strategies within those categories to be helpful in reducing job-related stress. There were selected coping strategies that were found to be unrealistic or difficult to apply given their personality (i.e., assertive, authoritative) or the types of situations that warrant a rapid response that is more closely allied with approach than avoidance coping. Nevertheless, the officers reported carrying out their coping strategies successfully, and expressed further interest in improving their understanding of learning new strategies. This was particularly important in relation to having the ability to know when to allow some situations to be perceived as irrelevant or unworthy of their time and when to remain vigilant and in control—a more approach style.

This exploratory study, reflecting both quantitative and qualitative data, provides credence to the approach-avoidance coping framework as an effective educational tool and source of reduced police stress. Future research is needed to examine the effect of coping skill interventions on selected outcomes of affect (e.g., perceived stress), job satisfaction, and performance. Learning proper coping skills, particularly when to use avoidance coping, is not inherent in law enforcement training programs, and yet, police work is among the most stressful professions. The combination of a noxious work environment, numerous sources of chronic and acute stress, and the lack of recovery from the job's inherent "storms" warrants the use of a combination of approach and avoidance coping styles, in both behavioral and cognitive forms. The varieties and complexities of avoidance coping were completely, but understandably, foreign to all 11 participants in this study.

The current findings are useful for improving our understanding of coping with police acute stress. Five forms of validation in this study were established; theoretical, evaluative, outcome, process, and catalytic forms of validity were met, as recommended by Mills (2003) for action research.

Theoretical validity was established by the changes in selected dependent variables, specifically perceived stress and perceived physical energy, based on the approach-avoidance coping framework. The officers were required to become familiar with the approach and avoidance forms of coping, each with cognitive and behavioral sub-dimensions. In addition, the officers were instructed on the best conditions under which to use approach and avoidance coping strategies. It is plausible to speculate that the officers used these coping options appropriately and judiciously. Evaluative validity was established by obtaining data that were objective, unbiased, and reflected treatment efficacy in terms of the effect of improved coping skills on the dependent measures.

Outcome validity was obtained in this study because the officers at least partially overcame dysfunctional coping habits and, instead, engaged in more efficacious coping strategies. In the present study, specific quantitative outcomes improved from pretest to posttest, suggesting adherence to program concepts. It must be recognized, however, that the relatively low sample size may have compromised the ability to obtain statistical significance on selected measures.

Process validity required the study to be conducted in a manner that reflected the competence of program leaders responsible for delivering coping information. Informal post-study verbal and online interactions with the participants about their experiences in the program indicated that the seminar was informative (they were each sent a copy of the PowerPoint), the coping skills intervention was learned and applied effectively, and that positive feelings emerged about the stress management coach.

Finally, catalytic validity requires that behavior change among the officers is based on their understanding of the study's primary objective of teaching effective coping skills following job-related acute stress. The officers 
in this study were apparently self-motivated to replace selected unhealthy coping habits that compromised their health and increased their stress level with more desirable routines. This conclusion reflects the $100 \%$ completion rate of this program among the 11 officers, all of whom found the program advantageous in reducing their job-related stress; there were no dropouts.

\section{Conclusion}

The results of this study showed that a coping skills intervention can be effectively implemented with police officers as a way to help them to manage their stress levels. Use of the approach-avoidance coping framework appears to be effective in promoting effective coping skills in law enforcement. While the small sample size was one limitation in this study (discussed earlier), it should be noted that the current participants, all volunteers, represented similar sources of excessive job-related acute stress combined with poor coping skills as other officers in the department. Whether the results of this study can be generalized to other male and female members of law enforcement and a larger sample among awaits further study.

\section{Acknowledgments}

The researchers acknowledge and greatly appreciate financial support for this study which was jointly funded by the Faculty Research \& Creative Activity Grant from Middle Tennessee State University and by the Murfreesboro (TN) Police Department, and Chief of Police, Mr. Glenn Chrisman.

\section{References}

Anshel, M. H. (2000). A Conceptual Model and Implications for Coping with Stressful Events in Police Work. Criminal Justice and Behavior: An International Journal, 27, 375-400. http://dx.doi.org/10.1177/0093854800027003006

Anshel, M. H. (2011). The Disconnected Values Model: A Brief Intervention for Improving Healthy Habits and Coping with Stress in Law Enforcement. In J. Kitaeff (Ed.), Handbook of Police Psychology (pp. 525-540). New York: Routledge Psychology Press.

Anshel, M. H., Kang, M., \& Miesner, M. (2010). The Approach-Avoidance Framework for Identifying Athletes’ Coping Style as a Function of Gender and Race. Scandinavian Journal of Psychology, 51, 341-349.

Anshel, M. H., Robertson, M., \& Caputi, P. (1997). Sources of Acute Stress and Their Appraisals and Reappraisals among Australian Police as a Function of Previous Experience. Journal of Occupational and Organizational Psychology, 70, 337-356. http://dx.doi.org/10.1111/j.2044-8325.1997.tb00653.x

Anshel, M. H., Umscheid, D., \& Brinthaupt, T. (2013). Effect of a Combined Coping Skills and Wellness Program on Perceived Stress and Physical Energy among Police Emergency Dispatchers: An Exploratory Study. Journal of Police and Criminal Psychology, 28, 1-14. http://dx.doi.org/10.1007/s11896-012-9110-x

Aumiller, G., Corey, D., Allen, S. Brewster, J., Cuttler, M., Gupton, H. \& Honig, A. (2007). Defining the Field of Police Psychology: Core Domains \& Proficiencies. Journal of Police and Criminal Psychology, 22, 65-76.

Behr, R. (2000). Under the Headset: Surviving Dispatcher Stress. Wildomar, CA: Staggs.

Bramson, R. M. (1981). Coping with Difficult People. Garden City, NY: Doubleday.

Clandinin, D. J., \& Connelly, F. M. (2000). Narrative Inquiry: Experience and Story in Qualitative Research. San Francisco: Jossey-Bass.

Cohen, S., \& Williamson, G. (1988). Perceived Stress in a Probability Sample of the United States. In S. Spacapan, \& S. Oskamp (Eds.), The Social Psychology of Health: Claremont Symposium on Applied Social Psychology (pp. 31-67). Newbury Park, CA: Sage.

Hart, P. M., Wearing, A. J., \& Headey, B. (1995). Police Stress and Well-Being: Integrating Personality, Coping and Daily Work Experiences. Journal of Occupational and Organizational Psychology, 68, 133-156.

Hassell, K. D., \& Brandl, S. G. (2009). An Examination of the Workplace Experiences of Police Patrol Officers: The Role of Race, Sex, and Sexual Orientation. Police Quarterly, 12, 408-430. http://dx.doi.org/10.1111/j.2044-8325.1995.tb00578.x

Jenkins, S. R. (1997). Coping and Social Support among Emergency Dispatchers: Hurricane Andrew. Journal of Social Behavior and Personality, 12, 201-216. http://dx.doi.org/10.1177/1098611109348473

Kirkmeyer, S. L. (1988). Coping with Competing Demands: Interruption and the Type A Pattern. Journal of Applied Psychology, 73, 621-629.

Krohne, H. W. (1993). Vigilance and Cognitive Avoidance as Concepts in Coping Research. In H. W. Krohne (Ed.), Atten- 
tion and Avoidance (pp. 19-50). Seattle, WA: Hogrefe \& Huber. http://dx.doi.org/10.1037/0021-9010.73.4.621

Mills G. E. (2003). Action Research: A Guide for the Teacher Researcher (2nd ed). Upper Saddle River, NJ: Merrill Prentice-Hall.

Roth, S., \& Cohen, L. J. (1986). Approach, Avoidance, and Coping with Stress. American Psychologist, 41, 813-819.

Rybicki, D., \& Nutter, R. (2002). Employment-Related Psychological Evaluations: Risk Management Concerns and Current Practices. Journal of Police Criminal Psychology, 17, 8-31. http://dx.doi.org/10.1037/0021-9010.73.4.621

Shepherd, M., \& Hodgkinson, P. E. (1990). The Hidden Victims of Disaster: Helper stress. Stress Medicine, 6, 29-35. http://dx.doi.org/10.1007/BF02807112

Slate, R. N., Johnson, W. W., \& Colbert, S. S. (2007). Police Stress: A Structural Model. Journal of Police and Criminal Psychology, 22, 102-112. http://dx.doi.org/10.1002/smi.2460060107

Wyllie, D. (2011). Implementing a Tactical Fitness Program. Police One.Com News. http://dx.doi.org/10.1007/s11896-007-9012-5

Zeidner, M., \& Saklofske, D. (1996). Adaptive and Maladaptive Coping. In M. Zeidner \& N.S. Endler (Eds.), Handbook of Coping: Theory, Research, Applications (pp. 505-531). New York: John Wiley \& Sons. 